\title{
The Balanced Scorecard: A Strategic Management Tool for Ranchers
}

\section{By Nicola M. Shadbolt}

he Balanced Scorecard is a commonly used strategy tool in business. Strategic management is an essential skill if long-term aims are to be achieved.

1 Yet neither can be discussed before they are put into context of a ranching business. This paper sets out to do this by first defining the different levels of management and the role of strategic management in particular. It then describes the role strategy tools play in strategic management with specific reference to the Balanced Scorecard, relating it to the multiple perspectives typical of farming and ranching businesses.

\section{Strategic Management}

The three levels of management that occur in farming and ranching businesses (described in Table 1) are operational (technical), tactical (middle management), and strategic (leadership). ${ }^{1}$ Operational management focuses on specific activities, and the outcome of the best operational managers (be they cowboys, fencers, tractor drivers, or electricians) is excellence. Their expertise is their power over employers and

This article has been peer reviewed. peers. Tactical management, on the other hand, determines within-year adjustments to a farm strategy (policy) so that it fits with the prevailing circumstances. Tactical managers need to deliver consistent results, a "no surprises" outcome, devise processes and systems that will enable resources to be efficiently organized, and use their authority to get things done. The final level is that of strategic management, which encompasses the leaders of the business. A distinction that is often made between managers and leaders is that it is the managers who improve the efficiency of the business and the leaders who improve its effectiveness. ${ }^{2}$ The best strategists are the big picture people and their outcome is not status quo but positive change. They make this happen through influencing others to buy into their dreams. Strategic management is different from other levels of management in several ways: it is nonroutine; nonprogrammable; unique and creative; ${ }^{3}$ more ambiguous, uncertain, and complex; ${ }^{4}$ and yet it has the greatest impact on the future of the business. ${ }^{5}$ Strategy defines the logical case for how value will be created for shareholders, and it defines actions and resource use. Inevitably, it is based on a set of assumptions about the future that must be put to the test.

Porth suggests that the strategic management process (Fig. 1) includes five interrelated tasks: to develop a mission

\section{Table 1. Levels of management ${ }^{1}$}

\begin{tabular}{llll} 
& Technical & Management & Leadership \\
\cline { 2 - 4 } Outcome & Excellence & Consistent results & Positive change \\
Focus & How (hands) do & What (head) organizes & Why (heart) dreams \\
Power & Expertise & Authority & Influence \\
Levels & Operational & Tactical & Strategic
\end{tabular}




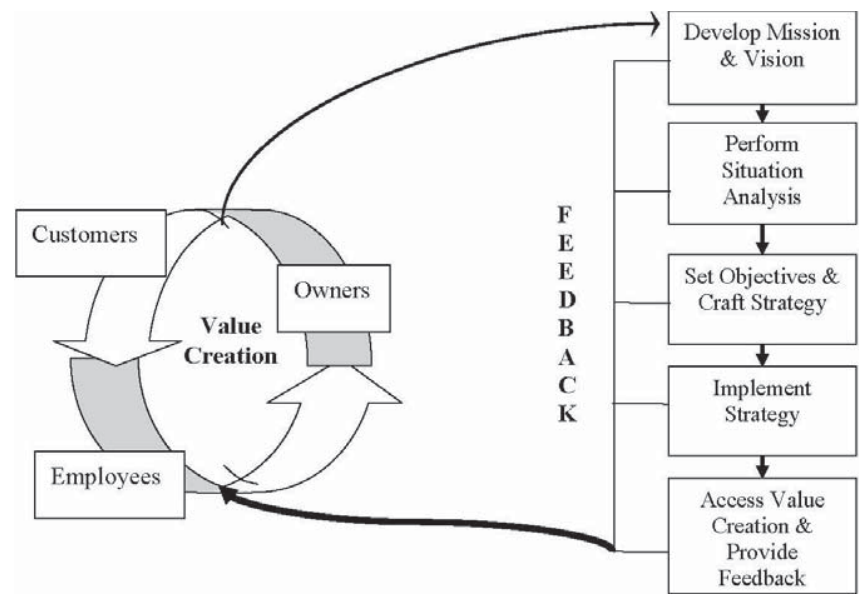

Figure 1. The strategic management framework. ${ }^{6}$

and a vision, to perform a situation analysis (internal and external audit), to set objectives and to craft the strategy, to implement the strategy, and to assess value creation and provide feedback. He suggests that the ultimate purpose of each of these tasks is to create value for the company's key stakeholders: employees, customers, and owners. ${ }^{6}$ The process illustrated in Figure 1 might appear to be a defined and formal process but in practice it can be haphazard and informal. ${ }^{7}$

The key words describing strategic management are summarized below: ${ }^{8}$

1. Continuous: the plan is not the final product

2. Systematic: the process has a deliberate and specific methodology and sequence of events

3. Process: the value of planning lies more in the journey than the destination, and from teamwork, vision, and commitment gained through the process

4. People: the process must involve the right people

5. Decisions: decisions must be made; as a result "decisionmaking is the most significant activity engaged in by managers"

6. Outcomes: the effects of the business on its customers and the outside world

7. How outcomes are to be accomplished: selecting the right road

8. How success is measured and evaluated: the plan will describe intended future outcomes either quantitatively or qualitatively, and it always defines criteria for success

In a larger organization it is expected that leadership is delivered by the CEO and the Board of Directors, management is delegated to the senior and middle managers, and operational issues are delegated to staff at the "coalface." In smaller companies such distinctions, although still relevant, can be lost. It is easy to understand how the most frequent issues that, by definition, are operational ones can dominate over less frequent ones. There sometimes is a strong focus at the operational and, sometimes, the tactical level of the business, and a weak strategic focus. ${ }^{1,9}$ These businesses run the risk of falling into the trap of being very efficient at getting the wrong job done.
To belittle ranch or farm managers for having this shortterm focus is to misunderstand the complexity of their role. Operational and tactical management are essential skills on all ranches and must be mastered. If the business is small, it is they who must master them, because delegation cannot occur. However, they must also deliver to the dream that they and their family have, so leadership skills are essential. Recognizing how their operational and tactical activities deliver to that dream by determining the cause-and-effect relationships that exist is an acquired activity.

\section{The Importance of Vision}

Although it is not the purpose of this paper to describe in detail the strategic management process, it is relevant to dwell for a moment on the "mission and vision" stage. There is significant debate in the literature as to what constitutes a mission and a vision. For family businesses, this author prefers to take the approach of ensuring the core values of the business (and family) are understood and reconciled before defining what they term the "organizational purpose." ${ }^{4}$ Family businesses frequently have stakeholders with opposing value sets. Thus it is important that those differences are recognized before a value set relevant to the business is devised. Gasson lists a number of goals and values commonly found in farming family businesses and groups them into four categories as follows: ${ }^{10}$

1. Instrumental (business) values: where farming is viewed as a means of obtaining income and security with pleasant working conditions

2. Social values: where farming is undertaken for the sake of interpersonal relationships in work

3. Personal (expressive) values: where farming is a means of self-expression or personal fulfilment

4. Intrinsic (lifestyle) values: where farming is valued as an activity in its own right

Studies of farmers' goals and objectives discussed by Gasson and Errington have shown that intrinsic aspects of being a farmer typically are ranked higher than the instrumental aspects. They conclude that autonomy, independence, survival, and succession thus mingle with the more orthodox economic issues. ${ }^{11}$

Examples of vision statements from New Zealand farms are shown in Table 2 . Note how clearly the differing value sets become obvious from the words they have chosen to use.

\section{The Balanced Scorecard as a Key Part of Strategic Management}

The shift from the industrial economy towards an economy characterized by intangible assets, such as knowledge and innovative capability, has increased the levels of complexity, mobility, and the uncertainty that organizations face. Atkinson summarizes that the transformation from the industrial age to the information age is signalled by increasingly sophisticated customers and management practices, escalating globalization, more prevalent and subtle product differentiation, and an emphasis on intellectual capital and enhanced 
employee empowerment. ${ }^{12}$ A range of new strategy tools and performance measurement frameworks have evolved to assist strategy implementation. Nonfinancial measures have combined with or replaced traditional financially oriented metrics as strategic controls providing useful short-term targets on the long-term strategic road. ${ }^{13}$

One such tool, the Balanced Scorecard, is described by Atkinson as arguably the dominant framework in performance management. ${ }^{12}$ Devised by Kaplan and Norton, it was proposed as an approach to tracking a firm's performance that takes into account process, innovation, and customer objectives as well as the financial position. ${ }^{14}$ In working with the scorecard they also found it performed an integrative function by bringing together disparate measures in a single report, and hence helped the senior management team to clarify and operationalize strategy. ${ }^{15}$ They identified significant weaknesses in performance management systems at that time that were dominated by short-term, backward-looking, or "lag" financial metrics which were internally oriented and not linked to organizational strategy. ${ }^{12}$ Based on case study research of leading companies, they concluded that financial numbers alone were no longer sufficient to run a business effectively because they lacked predictive power. They devised a scorecard with four perspectives that permitted a balance to be struck between short- and long-term objectives; between desired outcomes and the performance drivers of those outcomes; and between hard objective measures and the softer, more subjective, measures. ${ }^{8}$ In response to the tension that exists between the rigor necessary for effective strategy implementation and the flexibility required for timely strategic adjustment ${ }^{12}$ they also claimed that the Balanced Scorecard "...provides a framework for managing the implementation of strategy while also allowing the strategy itself to evolve in response to changes in the company's competitive market and technological environment..."16

The Balanced Scorecard has been so effective and widely accepted that the Harvard Business Review hailed it as one of the most influential management ideas of the 20th century. ${ }^{17}$ The first book of the series describing the framework has translations into more than 18 languages.

\section{Balanced Scorecard Framework}

According to Kaplan and Norton, a Balanced Scorecard should have the following components: ${ }^{16}$

Core vision: The value-based purpose that strategy delivers to the organization.

Perspectives: There are typically four perspectives: learning and growth, internal processes, customer, and financial. Others can be added based on specific needs. A perspective often represents a stakeholder category or point of view.

Objectives: An objective states how a strategy will be made operational. They usually form the building blocks for the overall strategy of the organization.

Measures: They must be quantifiable. They communicate the specific behavior to achieve the objective and become the
Table 2. Vision statements of several New Zealand family farm businesses

- To pursue excellence and growth in sustainable agriculture, thereby providing for diversification, succession, and a continuously improving standard of living for all stakeholders in the business.

- To have a farm business that is growing, is financially profitable, and is environmentally sustainable, while enabling us to maintain our lifestyle and enjoy time with our children and friends and continue our involvement in the community.

- To increase sustainable net income by being a preferred supplier of high-quality milk and dairy livestock, by adopting excellence in farm management practices and technologies, and by developing beneficial partnerships with our team of staff, while embracing the values of integrity, honesty, and the pursuit of knowledge.

- To grow the family farm business by profitably marketing quality products to ensure that the future generation has a viable farming business.

actionable statement of how the strategic objective will be accomplished. Lead measures are predictors of future performance (drivers), whereas lag measures are outcomes.

Strategic initiatives: These activities (discretionary investments or projects) will focus on the attainment of strategic results. All initiatives in an organization should be aligned with the strategy in the Balanced Scorecard.

Cause and effect linkages: It is similar to "if-then" statements. These cause-and-effect linkages should be explicit.

With each perspective Kaplan and Norton pose a question:

- Learning and Growth: "To achieve our vision, how will

we sustain our ability to change and improve?" This infers of course, that the business does have an ability to change and improve; for some, developing that skill might be the first initiative. The focus here is on the capacity of the business to learn and grow, improve its flexibility, and invest for future development.

- Internal Business: "To satisfy our shareholders and customers, what business processes must we excel at?" The question prompts the business to define critical skills and core competencies, processes, and technologies, both current and still to be developed.

- Customer: "To achieve our vision, how should we appear to customers?" How the customer currently perceives the business must be known before any improvement is targeted.

- Financial: "To succeed financially, how should we appear to our shareholders?" The impact of performance on traditional financial measures such as return on capital and cash flow, shareholder value and shareholder satisfaction are emphasised in this final perspective. ${ }^{16}$

Some authors suggest having only four perspectives is a weakness in the Balanced Scorecard. Haapasalo et al. identi- 


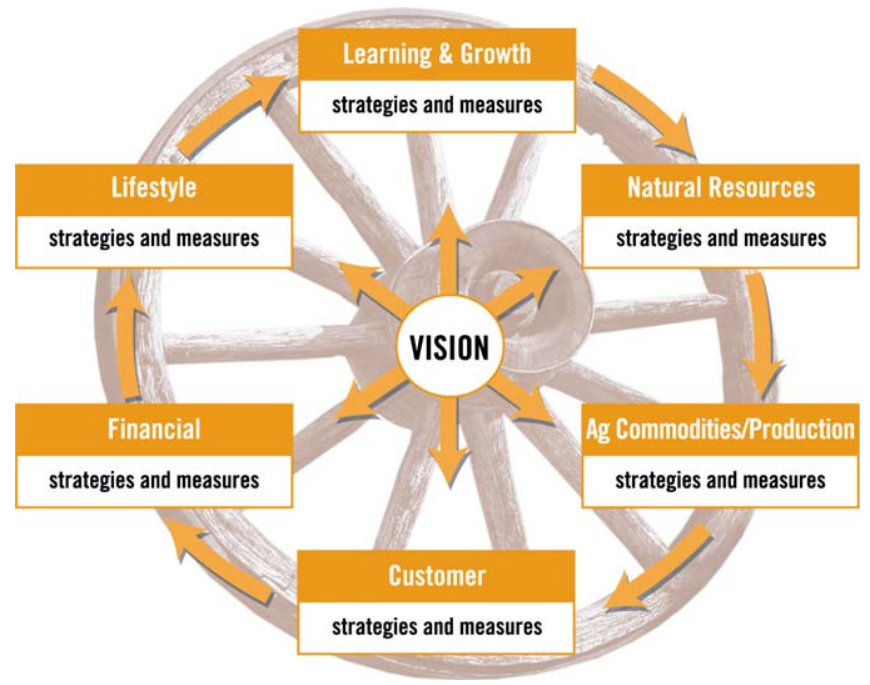

Figure 2. Relationships between parts of the Balanced Scorecard. ${ }^{23}$

fied additional perspectives such as human resources, environmental and supplier perspectives, and innovation processes, and then explained how each can be included in one or two of the original perspectives. ${ }^{8}$ Gifford added a fifth "core values" perspective. ${ }^{18}$ Russell added a supplier perspective in automobile companies. ${ }^{19}$ Similarly, Creelman emphasizes that organizations should not blindly adopt the normal four Balanced Scorecard perspectives, but rather choose the number of perspectives that reflect their own strategic needs. ${ }^{20}$ Some organizations have expanded or changed the basic model to include other perspectives relating to their business type (examples of this in the Finnish energy sector were found by Haapasalo), ${ }^{8}$ the community, or society. Others have changed the order of the perspectives. For example, not-for-profit organizations have reversed the roles of the financial and customer perspectives as the latter more accurately reflects their objectives. ${ }^{21}$ Working with on-farm agribusinesses Shadbolt et al. found that an extension of the customer perspective to include the suppliers (more of a supply chain approach) was relevant, as was an extension of the shareholder/financial perspective to include nonfinancial shareholder goals such as lifestyle and environmental/ethical issues. ${ }^{22}$ Dunn captured these issues by suggesting six perspectives suitable for ranch strategic management (Fig. 2) to ensure the lifestyle and environmental (natural resources) aspects of the business were given equal weight with the more traditional financial, livestock production, customer, and learning and growth. ${ }^{23}$

Therefore, the Balanced Scorecard allows executives to manage a company from several perspectives simultaneously. Shadbolt states it has evolved into a useful framework because it forces the perspectives of human resources (innovation, continuous improvement, and learning), internal processes (turning inputs into outputs), the market (customer relationships, product, and service criteria), and shareholders (profitability, return on assets, wealth, nonfinancial, and ethical goals) to be explored and the linkages between them to be determined. ${ }^{24}$ The term "Balanced Scorecard" reflects the balance between short- and long-term objectives, financial and nonfinancial measures, lag and lead indicators, and external and internal performance perspectives. ${ }^{25}$ It provides a balanced organizational assessment by recognizing a variety of stakeholder views.

The Balanced Scorecard design process builds upon the premise of strategy as hypotheses. Strategy implies the movement of an organization from its present position to a desirable but uncertain future position. Because the organization has never been to this future position, its intended pathway involves a series of linked hypotheses. The scorecard enables the strategic hypotheses to be described as a set of cause and effect relationships that are explicit and testable. ${ }^{26}$ An example of this for on-farm agribusiness was given by Shadbolt as she described how the assumptions made of the cause and effect relationship between process (farm practices) and state (environmental impacts) indicators could be explored. ${ }^{24}$

Having a sound vision for the business is the key to the success of the Balanced Scorecard. ${ }^{8}$ As already stated, a common vision is a challenge in farm family businesses where conflict often exists between business and family visions and purpose. ${ }^{10} \mathrm{~A}$ solution proposed by Andersson was separate visions for business and for farm family lifestyle issues and to add a fifth perspective to the Balanced Scorecard, called "life." ${ }^{27}$ However, having two visions could be divisive and lead to family business dysfunction. Atkinson identifies from the literature that in all businesses, regardless of size, strategic change requires a shared vision and consensus; failures are inevitable if competence, coordination, and commitment are lacking. ${ }^{13}$

The absence of goals or abundance of goals in any perspective gives a quick, visual indication of whether the business is "in balance." Key metrics are also specified for each goal, and include both the outcomes (lag indicators) and the drivers (lead indicators). If too many metrics are defined in a Balanced Scorecard, it too quickly turns from a management system into a monitoring system. If it is to be used effectively as a management tool with strategic purposes, the number of metrics must be low. ${ }^{8}$ Nonfinancial measures are usually drivers, informing the manager of likely future performance. For example, learning new knowledge and skills, a lag indicator for learning and growth, is a lead indicator of the farm staff's ability to ensure best practices at "harvest" are in place. ${ }^{22}$ Without investment in staff learning and personal growth, the business has less ability to deliver to the productquality specifications identified in its customer-related goals. The under-utilization of nonfinancial key performance indicators in business control was one of the key findings that led to the development of the Balanced Scorecard by Kaplan and Norton. ${ }^{14}$

\section{Making the Balanced Scorecard Work}

Knott defines the Balanced Scorecard as a strategy tool that involves substantial commitment of people and funds and 


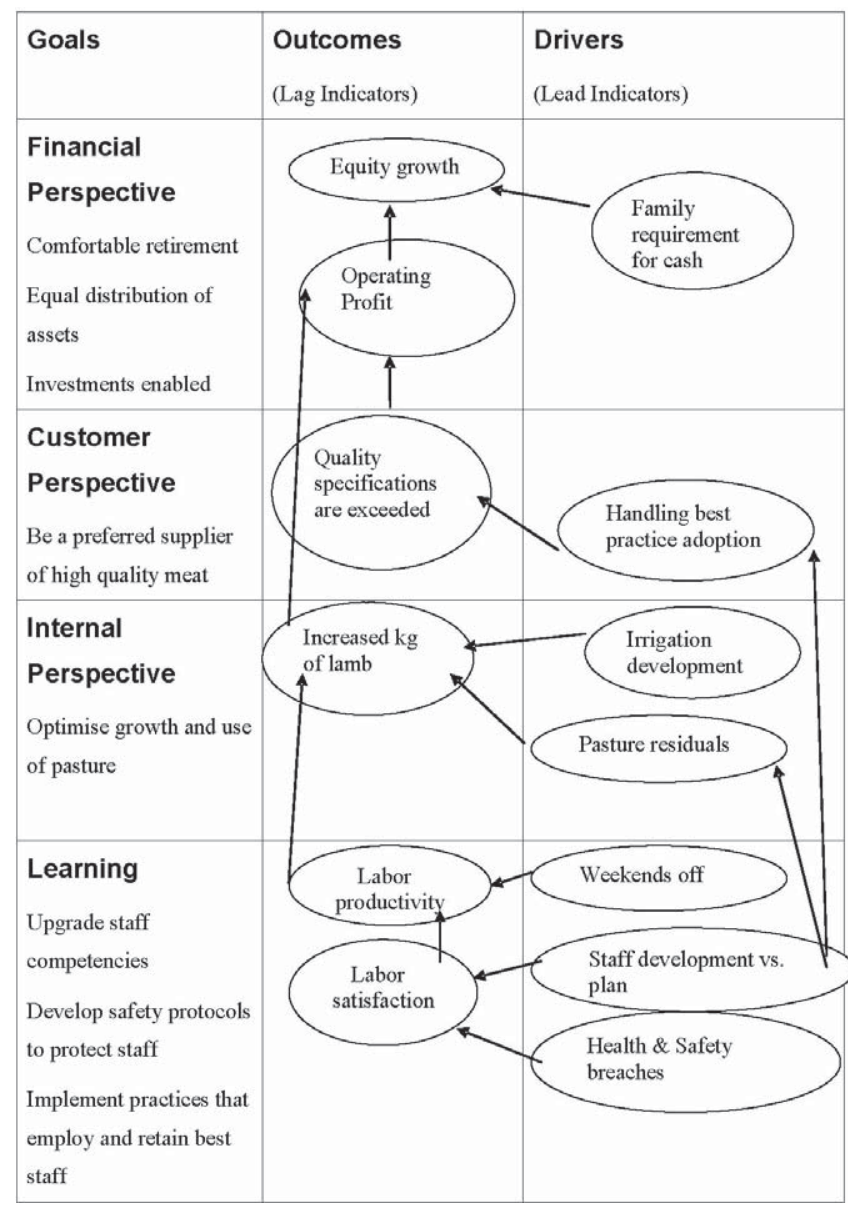

Figure 3. Balanced Scorecard for a pastoral farm business. ${ }^{28}$

has organization-wide implications. ${ }^{15}$ It requires systematic strategic planning activity and an holistic approach. Kaplan and Norton suggested the Balanced Scorecard be viewed as a template not a straitjacket so that it has flexibility and adaptive capacity. ${ }^{16}$ Knott suggests that flexibility and adaptive capacity is critical to its successful application in an organization. ${ }^{15}$

The Atkinson review on the role of the Balanced Scorecard in strategy implementation identifies some critical aspects to making it work: ${ }^{12}$

1. Begin with a full strategic appraisal and a clear articulation of the organization's strategic vision and objectives. This builds consensus and engenders learning.

2. Make explicit the cause and effect of a strategy. Convert strategic aims into tangible objectives and measures and identify where they interlink.

3. Implement the Balanced Scorecard participatively with measures identified and targets set cooperatively rather than imposed. This supports organizational learning and reflection and encourages interactive control through the testing of cause-and-effect relationships.

4. Encourage Balanced Scorecards at every level of an organization to enable middle-management engagement. Haapasalo et al., in their observation of Balanced Score- card in use in the energy sector, concur on the above and also add the necessity for each company to create its own metrics. If this is not done, the link to strategy can disappear and the connection to management is lost. The metrics must also evolve as the organization changes. They state there should be profound discussion over different perspectives; again the advice is to determine what is right for each company-do not use other company or industry lists. They state one of the most important aspects of implementing the Balanced Scorecard is the learning process inside the organization as it facilitates in-depth discussion about the business' vision, strategy, and critical success factors and translates them into specific measures and objectives in action. ${ }^{8}$

When applied to on-farm agribusinesses it has proven to provide an acceptable framework with which to capture the more holistic nature of farm systems and enable both financial and nonfinancial (including nonbusiness) goals to be managed. ${ }^{1,22}$ Shadbolt further suggests how, in a policy context, it can provide a framework to enable a specific plan, such as an environmental plan, to fit within the overall business. ${ }^{24}$

Figure 3 provides an example of a scorecard for a pastoral farm business in New Zealand. ${ }^{28}$ The simplicity of the scorecard should not be taken as being an indication of lack of in-depth discussion and debate on strategy and metrics, but instead as an illustration of how it can be a useful report that clarifies and operationalizes strategy. It illustrates the causeand-effect relationships and how they build from each level. The starting point is learning and growth. Without human capability and capacity strategy cannot be implemented. It then leads to the management of natural resources and production through which market needs are met. The result of meeting these needs is that financial targets are met and this, along with other nonfinancial outcomes, delivers to the lifestyle requirements of the family.

\section{Conclusions}

It is important to recognize that a strategy tool such as the Balanced Scorecard is likely to assist with part of the activity rather than provide a substitute for the capabilities and experience of the manager. It does not provide a blueprint, but can act as a guide to thinking and a starting point for structuring the activity. ${ }^{15}$ There is a risk that the tool or framework that a manager uses will channel or constrain thinking as it focuses and guides, in which case alternative tools or adaptation of the tool might be required to ensure robust strategy is crafted. Users of the Balanced Scorecard should keep this in mind; the tool is not a recipe for success but a means by which a business can assess its direction, craft strategy, and define success. Its application will vary from ranch to ranch according to the skills and motivation of the owners and managers. For some it might just guide thinking and debate. For others it will provide a framework that can enable planning greater detail on implementation and ongoing control.

The framework the Balanced Scorecard provides enables the components of strategy to be identified and the interac- 
tions between the components to be visualized. It forces goals to be linked to the vision and actions to be linked to goals. It enables ranch businesses to look beyond finance and production to include multiple perspectives. Ranchers must not only define how success is measured in the Balanced Scorecard but also what the drivers of positive change really are-what are the cause and effect relationships in the business. And, finally, to make best use of the Balanced Scorecard, keep it flexible, simple, and practical.

Author is Senior Lecturer in Farm and Agribusiness Management, Massey University, Palmerston North, New Zealand, N.M.Shadbolt@massey.ac.nz.

\section{References}

1. Shadbolt, N. M., and M. Rawlings. 2001. Successful benchmarking by balanced planning and identifying key performance indicators for goal attainment in dairy farming. Melbourne, Victoria, Australia: Dairy Research and Development Corporation (Australia). Project Code: MUNZ001. 238 p.

2. Duncan, W. J. 1999. Management: Ideas and actions. New York, NY: Oxford University Press. 226 p.

3. Harrison, E. F. 1999. The managerial decision making process. Boston, MA: Houghton Mifflin. 555 p.

4. Johnson, G., K. Scholes, and R. Whittington. 2005. Exploring corporate strategy: Text and cases. 7th ed. London, United Kingdom: Pearson Education Ltd. 1033 p.

5. Shadbolt, N. M., and A. Bywater. 2005. The dimensions of management. In: Farm management in New Zealand. N. M. Shadbolt and S. Martin S. [eds.]. Oxford University Press. 424 p.

6. Porth, S. J. 2003. Strategic management: A cross-functional approach. Upper Saddle River, NJ: Prentice Hall. 266 p.

7. Cuthbert, R. H., and T. R. R. Johnston. 1997. The strategic planning process of agricultural niche marketers: A case study approach. In: Proceedings of the 11th International Farm Management Congress; 1997. Calgary, Alberta, Canada: University of Calgary. p. 961-975.

8. Haapasalo, H., K. Ingalsuo, and T. Lenkkeri. 2006. Linking strategy into operational management. Benchmarking: An International Journal 13(6):701-717.

9. Doonan, B. M. 2001. Strategic planning in the dairy industry - the Tasmanian experience. Proceedings of the South Africa Large Herds Conference. Port Elizabeth, South Africa; 5-7 February 2001. p. 27-42.

10. GAsson, R. 1973. Goals and values of farmers. Journal of Agricultural Economics 24:521-537.

11. Gasson, R., and A. Errington. 1993. The farm family business. Wallingford, UK: CAB International. 300 p.

12. Atrinson, H. 2006. Strategy implementation: a role for the balanced scorecard? Management Decision 44(10):1441-1460.
13. Bungay, S., and M. Goold. 1991. Creating strategic control systems. Long range planning 24(3):32-39.

14. Kaplan, R. S., and D. P. Norton. 1992. Using the balanced scorecard as a strategic management system. Harvard Business Review 70(1):71-80.

15. Knotт, P. 2006. A typology of strategy tool applications. Management Decision 44(8):1090-1105.

16. Kaplan, R. S., and D. P. Norton. 1996. The balanced scorecard-measures that drive performance. Harvard Business Review 74(1):1-9.

17. Siввет, D. 1997. 75 years of management ideas and practices 1992-1997. Harvard Business Review 75(5):2-13.

18. Gifford, J. D. 2000. Small orange juice processor gets big results with the balanced scorecard. Balanced Scorecard Report 2(5):8-10.

19. Russell, R. 2003. The international perspective: balanced scorecard usage in Europe. Balanced Scorecard Report 5(3):13-14.

20. Creelman, J. 1998. Building and implementing a balanced scorecard-international best practice in strategy implementation. London, United Kingdom: Business Intelligence Ltd. $362 \mathrm{p}$.

21. Atkinson, A., And M. Epstein. 2000. Measure for measure: realizing the power of the balanced scorecard. CMA Management 74:23-28, September.

22. Shadbolt, N. M., N. Beeby, B. Brier, and J. W. G. GardNER. 2003. A Critique of the use of the balanced dcorecard in multi-enterprise family farm businesses. Proceedings of the 14th International Farm Management Congress; 10-15 August 2003; Perth, Australia. Part 1, p. 602-609.

23. Dunn, B. H., R. N. Gates, J. Davis, and A. Arzeno. 2006. Using the balanced scorecard for ranch planning and management: setting strategy and measuring performance. Brookings, SD: South Dakota State University. EC922. 30 p.

24. Shadbolt, N. M. 2004. Agri-environmental indicators put into perspective: their fit and relationship with other relevant farm business indicators. In: N. Fraser [ed.]. Farm management indicators and the environment. Proceedings of an OECD Expert Meeting; March 2004; Palmerston North, New Zealand.

25. Hepworth, P. 1998. Weighing it up - a literature review for the balanced scorecard. Journal of Management Development 17(8):559-563.

26. Kaplan, S. R., and D. P. Norton. 2000. The strategy-focused organization: How balanced scorecard companies thrive in the new business environment. Boston, MA: Harvard Business School Press. 400 p.

27. Andersson, P. 2002. Competence development program for the farmer with reference to life as well as business. Proceedings of the 13th International Farm Management Association Congress, 7-12 July 2002; Wageningen, The Netherlands.

28. Shadbolt, N., and S. Martin. 2005. Farm management in New Zealand. New York, NY: Oxford University Press. 119 p. 